\title{
A CASE OF CONGENITAL HYPERTROPHIC PYLORIC STENOSIS
}

\author{
BY
}

\author{
WILFRID GAISFORD, M.D., M.R.C.P., \\ Assistant Physician to the East London Children's Hospital.
}

This case is reported because it presents some unusual features which, so far as I am aware, have not previously been encountered, namely, relapse of pyloric hypertrophy after operation, and the appearance of signs of congenital heart disease after blood transfusion.

\section{Clinical report.}

Eileen L., a female infant born normally at full term, was admitted at the age of 3 weeks to the East London C'hildren's Hospital on May 19th, 1930.

She was the first child of healthy parents. Vomiting after each feed, with increasing constipation, had been noticed for 7 days previous to admission and had led to weaning and the usual rapid succession of proprietary foods. For 3 days constipation had been absolute.

On admission she was moderately well-nourished, and examination revealed marked visible gastric peristalsis and a definite tumour in the region of the pylorus. A water feed was forcibly ejected to a considerable distance. There was no other physical abnormality. It was specifically noted that the heart was normal in size and position, and the sounds clear. The turgor of the skin over the abdomen being poor, $125 \mathrm{c.cm}$. of combined solution ${ }^{1}$ were administered subcutaneously; this was quickly absorbed, with improvement in her general condition. Feeds consisting of whole lactic acid milk (cultured) with 10 per cent. of mixed carbohydrates (six feeds of 75 c.cm. at 4 -hourly intervals), and thickened by the addition of 20 per cent. barley flour were prescribed. Atropine was also administered, flushing of the skin being attained at 7 minims of a $1 / 1000$ solution of atropine sulphate. Vomiting was unabated and operation was consequently deemed advisable. The weight at this time was $6 \mathrm{lb} .7 \mathrm{oz}$.

On May 21st, Mr. Acton Davis performed a Fredet-Rammstedt operation according to the technique recommended by Clopton and Hartmann². The stomach was found to be dilated and the pyloric tumour was about $\frac{1}{2}$-in. in length.

Three hours after her return to the ward the infant received $80 \mathrm{c.cm}$. of her father's blood intravenously and her condition, at no time very serious, improved considerably. The following day she received a second transfusion of $60 \mathrm{c.cm}$.

Some regurgitation of food occurred for the first few days, but this ceased entirely after five days, and there were 3 or 4 normal stools in every 24 hours. She was discharged on June 1st, 11 days after operation, apparently in good condition, though she had only gained $1 \mathrm{oz}$. in weight, which at this time was $6 \mathrm{lb} .8 \mathrm{oz}$.

On June 6 th, 5 days after discharge, she was re-admitted with the history that vomiting had ('ommenced after she had been home about 36 hours, and hat increased in frequency till it was as bad as when she was originally admitted. The bowels, however, had continued to be regular. She had lost weight, being now only $6 \mathrm{lb}$. $3 \mathrm{oz}$. Examination still revealed visible gastric peristalsis but no tumour could be felt, perhaps because palpation was rendered difficult by the recent operation scar. Vomiting after a test feed was projectile. The heart and lungs, as before, showed no abnormality nor was there any evidence of parenteral infection to account for the vomiting. She was again given thickened feeds and atropine, and improved somewhat, weighing $6 \mathrm{lb}$. $12 \mathrm{oz}$. on June 15th. Stools averaged 4 daily and were normal in character. 
Vomiting, however, persisted, and on this account Mr. Acton Davis decided to open the abdomen and inspect the pylorus, and on June 16th, i.e., 26 days after the first operation, this second operation was performed. The pylorus was found to have hypertrophied considerably, extending proximally as a new sphincter for about $\frac{1}{3}$-in. from the gastric end of the first incision, which was still clearly defined. The new pylorus was in every respect similar to the first, being pearly white in colour and cartilaginous in consistence.

Fig. 1 represents the tumour as found on May 21st, and the interrupted line indicates the incision then made. Fig. 2 shows the findings on June 16th, the continuous line indicating the incision made at the second operation.

The hypertrophied fibres were divided in their entire length and the abdomen closed in the usual manner. As the post-operative condition was excellent no supportive therapy was necessary. The patient gained weight steadily till July 6 th, at which time she weighed $7 \mathrm{lb} .12 \mathrm{oz}$. and was taking six feeds of $120 \mathrm{c.cm}$. daily without any vomiting, and having from 3 to 4 normal stools in the 24 hours.

From this date she commenced to go downhill, losing weight, vomiting frequently, and having from 7 to 10 loose stools every day. On July 11th, both tympanic membranes were definitely reddened and bilateral myringotomy yielded sero-purulent fluid from each ear. Her general condition had become so poor that it was decided to give a blood transfusion, and on

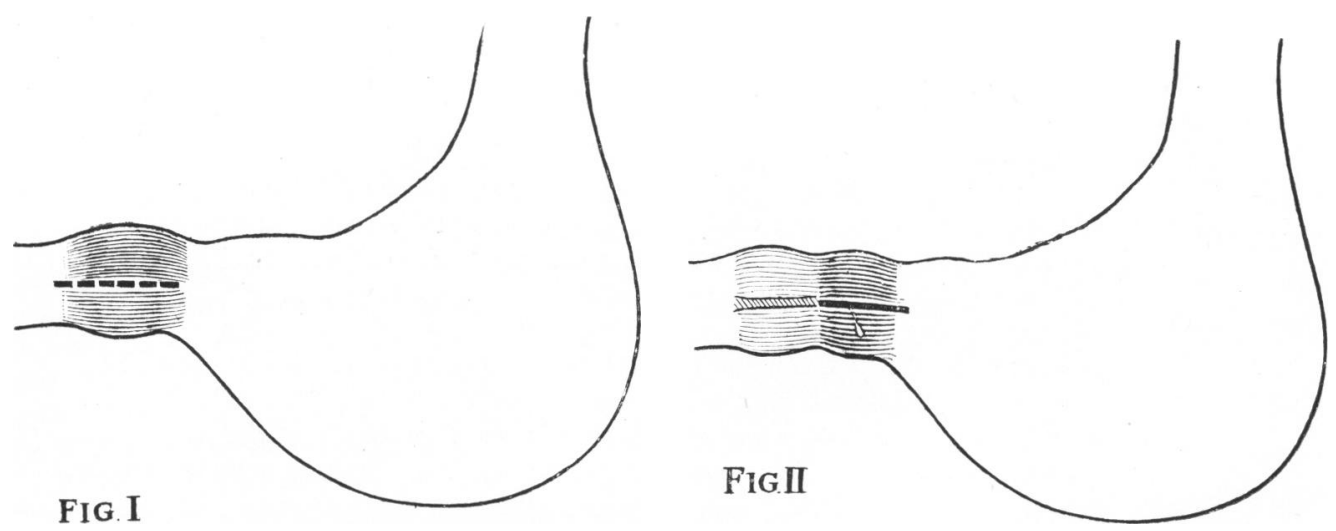

FIf. 1. Condition of pylorus and site of incision at the first operation.

Fic. 2. Condition of pylorus and site of incision at the second operation, 26 days later.

July 12th she received 100 c.cm. of her father's blood intravenously, followed some hours later by $175 \mathrm{c.cm}$. of 5 per cent. dextrose subcutaneously, and her general state was considerably improved thereby.

On July 14th examination of the chest revealed the presence of a loud harsh bruit all over the precordia, audible also over the back, with its maximum intensity just to the left of the left border of the sternum in the 4th intercostal space. There was no appreciable enlargement of the area of cardiac dullness, neither was there any cyanosis or dyspnœa. The bruit remained constant till her discharge on July 22 nd at which time she was in excellent health and weighed $8 \frac{1}{2} \mathrm{lb}$.

Subsequently she attended the out-patient department of the hospital regularly every 2 or 3 weeks, and developed normally. By October 6 th, she weighed $14 \mathrm{lb}$., and was taking 5 feeds of $210 \mathrm{c.cm}$. daily. At each attendance her cardiac status was carefully considered and it became apparent that the bruit was gradually disappearing, first becoming fainter, and then more localized, and finally on December 11 th it was quite inaudible. At no time had she any symptoms, nor was her development in any way altered, her weight on December 11th, at the age of 8 months, being $18 \mathrm{lb} .1 \mathrm{oz}$. The average weight for this age is $18 \mathrm{lb}$. (Camerer). Subsequent repeated examination has failed to disclose any cardiac abnormality, both sounds being clear and of good quality. 


\section{Discussion.}

The chief points of interest in this case are the development after operation of a second pyloric tumour on the proximal side of the first, and of a cardiac lesion following blood transfusion.

The first is probably to be explained by the escape of a minute ring of the fibres at the gastric end of the pylorus at the first operation. Mr. Acton Davis concurs in this opinion and thinks his original incision, while clearing the pyloro-duodenal junction adequately, did not extend sufficiently high at the gastric end. This may be accounted for by the relaxed condition of the stomach at the time of operation (lavage had immediately preceded it). Had the stomach been in a state of spasm the most proximal hypertrophied fibres would probably have stood out more clearly and the point at which it was safe to end the incision would have been more easily defined.

This ring of fibres may have led to spasm, which gradually increased until further hypertrophy, involving more and more fibres at the lower end of the stomach, resulted in the formation of the tumour found at the second operation.

The time elapsing before the development of the secondary tumour was almost identical with the time elapsing between birth and the original operation (23-26 days), and the second tumour was very nearly the same size as the first. Wollstein ${ }^{3}$ performed autopsies on 25 infants who had been operated on for pyloric stenosis by the Fredet-Rammstedt method and who had died at varying times from 24 hours to 2 years after operation. She found that the sear on the pylorus gradually disappeared; after 10 days the scar was still wide, but after 25 days there was no depression appreciable though the scar was still visible, and the pylorus was but little firmer than normal.

Fredet ${ }^{4}$ reported a case on which he had operated successfully 3 months previously and which had died of broncho-pneumonia. At autopsy there was no trace of the operative incision on the pylorus, but the pylorus still felt slightly thickened.

In the present case, after 25 days, the scar was still wide and the original pyloric tumour quite firm to the touch. Wollstein has shown that the hypertrophied muscle fibres take no part in the healing process, but that this oceurs by contraction of fibrous connective tissue from the serous and submucous coats. The process of healing may have been delayed in the present case by the continued existence of a sphincter proximally.

With regard to the cardiac condition, it is probable that the third transfusion, which was the largest, in some way altered the intracardiac pressure so that a defect in the septum, most likely at the foramen ovale, previously so small as to give rise to no signs clinically, became enlarged to pathological proportions. With the continued growth of the infant this opening gradually re-closed.

In over 100 infants receiving one or more transfusions during the past year at the East London Children's Hospital this was the only case in which any such occurrence was noted. The average quantity of blood injected was 10 c.cm. per lb. of body weight, but in the present case this was increased 
to $15 \mathrm{c} . \mathrm{cm}$. per $\mathrm{lb}$. There are two possible causes of the cardiac phenomenon here noted, first that the quantity was excessive, secondly that the rate of flow was too rapid. It would appear doubtful if the extra quantity of blood could greatly increase the intracardiac pressure; there were no signs of right heart stress following the transfusion, and the long duration of the murmur is a further objection. With regard to the rate of flow, this was no faster than usual, the $100 \mathrm{c.cm}$. being injected in approximately 20 minutes. Robertson and Brown ${ }^{4}$ stated that the rate of flow should not exceed $10 \mathrm{c.cm}$. per minute and they gave $120 \mathrm{c.cm}$. to a $6 \frac{1}{2}-\mathrm{lb}$. pyloric stenosis baby who was 5 weeks old with strikingly good results. They had one fatality, in a 4-lb. baby, thought to be due to excessive speed of administration, but in that case death was instantaneous from rapid over-distension of the right heart.

It is unfortunate that in the present case blood counts were not made before and after transfusion, nor was a radiogram of the chest taken, for these might have given some help in elucidating the problem.

I am indebted to Mr. K. J. Acton Davis for permission to publish this case which was admitted under his care ; and to Dr. Leonard Findlay for his advice and suggestions.

\section{REFERENCES.}

1. Hartmann, A. F., Colorudo Med., Denver, 1929, XXV1, 373.

2. Clopton, M. B. \& Hartmann, A. F., Surg. Gynec. Obst., ('hicago, 1928 XLV11, 527.

3. Wollstein, M., Am. J. Dis. Child., Chicago, 1922, XXIII, 512.

4. Lesne, Fredet, \& Coffin, Bull. Soc. de Pediat. de Paris, Paris, 1929, XXVII, 31.

5. Robertson, L. B. \& Brown, A., Canad. Med. Ass., Montreal, 1915, V, 298. 